\title{
Cool North European summers and possible links to explosive volcanic eruptions
}

\author{
P. D Jones, ${ }^{1,2}$ T. M. Melvin, ${ }^{1}$ C. Harpham, ${ }^{1}$ H. Grudd, ${ }^{3}$ and S. Helama ${ }^{4}$ \\ Received 7 January 2013; revised 1 May 2013; accepted 22 May 2013; published 25 June 2013.
}

[1] Exactly dated tree-ring measurements such as ring width (TRW) and maximum latewood density (MXD), which are sensitive to summer temperatures, can provide possible routes to investigate the occurrence of hemispheric-wide cool summers that might be linked to explosive tropical volcanic eruptions. These measurements can provide much longer records than the instrumental period, enabling much longer periods to be assessed and offers the potential to look at much larger eruptions than recorded over the last 200 years. This paper looks at TRW evidence from Northern Fennoscandia extending over the last 7500 years, using two independently produced chronologies from northern Sweden and northern Finland. TRW is less responsive than MXD to cool summer temperatures, but MXD is only available for the last 2000 years. Additionally, looking at a relatively small location, compared to the Northern Hemisphere average, adds considerable noise. Progress in this area is likely to be made by developing more millennial-long TRW series across northern high latitudes or being able to develop MXD series from the sub-fossil material, which comprises most of the samples prior to the last 1000 years. The three most extreme negative values for the region for the last 2000 years are 1601, 542, and 1837, although the latter is not extreme in a long instrumental record for the region. The most extreme year of all occurred in $330 \mathrm{BC}$. Of the 20 most extreme negative years, nine occurred during the AD years with the remaining 11 occurring during the prior 5500 years.

Citation: Jones, P. D., T. M. Melvin, C. Harpham, H. Grudd, and S. Helama (2013), Cool North European summers and possible links to explosive volcanic eruptions, J. Geophys. Res. Atmos., 118, 6259-6265, doi:10.1002/jgrd.50513.

\section{Introduction}

[2] Studies of the impacts of explosive volcanism on the surface temperature record of the Earth have been undertaken for many years [see, e.g., Sear et al., 1987, and references therein]. How these events cool surface air temperatures, particularly in the summer half year, and which types of events are likely to cause the greatest impacts have been extensively studied (see the review by Robock, [2000]). Knowledge is advanced by each new major eruption, particularly after the eruption of Mt. Pinatubo in the Philippines in June 1991. The effect on surface air temperatures has been illustrated by using composites of the major events, a technique referred to as superposed epoch analysis (SEA), [see Robock, 2000]. Significant cooling for the Northern Hemisphere (NH) land average is evident in the following two to three summer half

\footnotetext{
${ }^{1}$ Climatic Research Unit, School of Environmental Sciences, University of East Anglia, Norwich, UK.

${ }^{2}$ Center of Excellence for Climate Change Research, Department of Meteorology, King Abdulaziz University, Jeddah, Saudi Arabia.

${ }^{3}$ Bolin Centre for Climate Research, Department of Physical Geography and Quaternary Geology, Stockholm University, Stockholm, Sweden.

${ }^{4}$ Northern Unit, Finnish Forest Research Institute, Rovaniemi, Finland.

Corresponding author: P. D. Jones, Climatic Research Unit, School of Environmental Sciences, University of East Anglia, Norwich NR4 7TJ, UK. (p.jones@uea.ac.uk)

(C)2013. American Geophysical Union. All Rights Reserved. 2169-897X/13/10.1002/jgrd.50513
}

years [Jones et al., 2003]. Winter months tend to show little cooling, with some events showing evidence of warming in this season [Robock and Mao, 1992]. The sparsity of events through time (roughly one per decade) has led to a number of studies looking at longer instrumental records from Europe to develop a larger sample [see, e.g., Jones et al., 2003]. Even here the number of major events is not dramatically increased for the period 1750 to 1880 compared to the period since 1880 . Additionally, the spatial reduction from the $\mathrm{NH}$ to the European scale increases the noise, making cooling less significant. To dramatically increase the sample size requires the use of proxy data (principally from trees and ice cores), but the drawback of this is that the impacts are just felt at a few locations from where the proxy records are sourced.

[3] The most extensive study of potential impacts of volcanic events over longer periods used maximum latewood density (MXD) measurements from coniferous tree rings sampled across the land areas of the Northern Hemisphere north of $20^{\circ} \mathrm{N}$ [Briffa et al., 1998], extending previous work by Jones et al. [1995]. The sampling in this study focused on the high-latitude and high-elevation regions where coniferous trees dominate and tree growth is controlled primarily by summer warmth. The study only extended back to AD 1400 as before this date, the number of locations becomes too sparse to develop reliable spatial averages. Negative extreme values of MXD are clearly related to known volcanic events (see Simkin et al., [1981]; Simkin and Siebert, [1994]; and Siebert 
Table 1. Location and Dates (Eruption Year) of the Tropical and Higher Latitude NH Eruptions ${ }^{\text {a }}$

\begin{tabular}{|c|c|c|c|}
\hline \multicolumn{2}{|c|}{ Tropical } & \multicolumn{2}{|c|}{ Higher Latitude } \\
\hline Unknown & 1809 & Shikotsu & 1739 \\
\hline Tambora & 1815 & Laki/Asama & 1783 \\
\hline Cosiguina & 1835 & St. Helens & 1800 \\
\hline Krakatau & 1883 & Sheveluch & 1854 \\
\hline Santa Maria ${ }^{b}$ & 1902 & Ksudach & 1907 \\
\hline Agung & 1963 & Novarupta & 1912 \\
\hline El Chichón & 1982 & Bezymianny & 1956 \\
\hline Pinatubo & 1991 & & \\
\hline
\end{tabular}

${ }^{\mathrm{a}}$ Table is reproduced from Table 1 of Jones et al. [2003]. Full details of these eruptions are given in the study by Simkin and Siebert [1994].

${ }^{\mathrm{b}}$ There were also two VEI eruptions of four in the Caribbean in this year (Pelée and Soufriere).

et al., [2011] for lists of known and suspected events) that occurred during the year before or in the current year of tree growth. Most of the major volcanic events (based on the volcanic explosivity index, VEI, [Newhall and Self, 1982]) are evident, but there are some very negative years that do not coincide with known volcanic events. A full list of major volcanic events is given in Table 1, which is an exact copy of Table 1 from Jones et al. [2003]. There have been no major events in the last 10 years.

[4] The purpose of this paper is to use the annually resolved records of tree-ring widths (TRW) from two separate collections from northern Sweden and northern Finland to examine extreme low-growth years of temperature-sensitive tree growth. The two exactly cross-dated chronologies were independently developed from living and sub-fossil tree-ring material in the two regions, which are about $300 \mathrm{~km}$ apart. The chronologies extend back about 7000 years, so it is possible to examine the incidence of low-growth years in these trees over a much longer period to determine if the instrumental period is characteristic of typical eruption frequency and whether major events similar to the largest eruption of the last 200 years (Tambora in 1815) can be clearly seen in earlier periods. It must be remembered that this study looks at TRW and not MXD and that it is looking at a small part of the world - northern Fennoscandia. Jones et al. [2003] showed that extending studies with longer European instrumental temperature data had to confront additional noise with the smaller scale region. This will be further tested with the further reduction to northern Fennoscandia and the use of only TRW data. Section 2 discusses the development of the tree-ring records used together with a long instrumental record from the region that extends back to the early 19th century. Section 3 introduces the methodology used in assessing both records looking for extremely narrow ringwidth years and hence cool summers. Section 4 discusses the results, and Section 5 concludes.

\section{Tree-Ring and Instrumental Data Used}

[5] Tree-ring width measurements from living and subfossil material collected over the last 40 years have been independently cross-dated from two regions of Northern Fennoscandia (around Lake Torneträsk in northern Sweden and from across Finnish Lapland). The development of the long chronologies that extend back over 7000 years has been documented in numerous publications by the two groups
(Grudd et al., [2002] and Melvin et al. [2013] for Sweden and Eronen et al., [2002] and Helama et al., [2008] for Finland). The number of trees used for each chronology varies considerably through time. There are many more for more recent times when the principal constituent is living trees, but numbers are high for some earlier periods also. Signal quality is dependent on tree count in each year. The major difference between the two independent sets of tree-ring measurements is that there are more individual sets of measurements from Finland compared to Sweden. This greater sampling will be taken into account when the two series are merged for some of the later analyses.

[6] Instrumental records in northern Fennoscandia are relatively numerous with many series extending back to the mid- to late-19th century. Much earlier recording has been undertaken in the Haparanda area (referred to as Tornedalen) close to the Swedish/Finnish border at the head of the Gulf of Bothnia. Using these earlier records, Klingbjer and Moberg [2003] developed a much longer monthly instrumental record back to 1802 , which is complete apart from a completely missing year in 1815 . To use the full record back to 1802 , we insert an average summer value for 1815 based on the average of the values for 1810-1814 and 1816-1820. The sites of the early records were well documented, so the study used temperature loggers at these locations to help them determine adjustment factors (temperature differences) to relate these records to the modern Haparanda site. There might be exposure issues with the summer half-year temperatures measured prior to about 1870 due to the possible direct effect of the sun on the early instruments. This effect has been quantified for Alpine regions [Böhm et al., 2010], but there are just suspicions for this region and no real possibilities for developing definitive corrections. Later, we will subject this long instrumental record to the same type of analysis as the long TRW series. This method of assessment used emphasizes the high-frequency variations, so the exposure issues are not an important factor.

\section{Methods Used to Assess Unusual Growth in the TRW Tree-Ring Series and Their Links to MXD}

[7] As the aim of this study is to look at high-frequency variations in the tree-ring growth, we use a similar standardization method to that used by Larsen et al. [2008]. Measurement series are converted to tree-index series using a 10-year high-pass spline, signal-free standardization [Melvin and Briffa, 2008]. This is achieved by first fitting a 10 -year spline to each constituent measurement series and then dividing the measurement data by the fitted values to yield dimensionless index series for each tree. These tree indices are then averaged in correct calendrical alignment to produce a mean chronology series. Using the signal-free method, the average chronology is iteratively removed from the measurement series to ensure that the fit of the smoothing splines (which defines the multidecadal and longer variability to be removed from the measurements) is not locally distorted by the presence of any abrupt shifts in the chronology values. Each mean chronology series is additionally adjusted (using the method developed by Osborn et al. [1997]) for possible changes in variance that might result from the variable number of tree indices available through the length of each chronology. One of the reasons for using this 


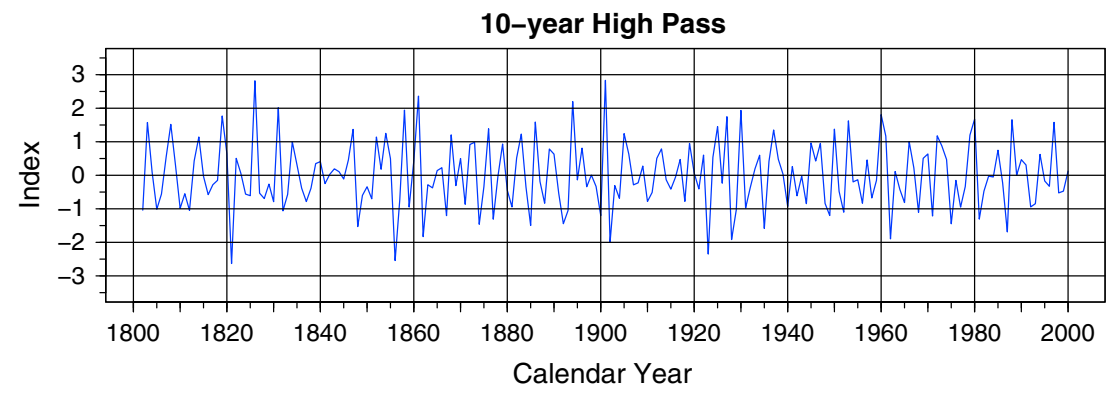

Figure 1. Residuals from the 10-year high-pass spline applied to the June-August (JJA) average temperature from Haparanda/Tornedalen, for the period 1802 to 2000.1815 is an average value (based on the average for 1810-1814 and 1816-1820) as this summer was not recorded.

high-frequency type of standardization is that trees can "subsidize" the growth of rings in a poor year with stored resources from earlier years, thus spreading the signal from individual events across more than one growth ring. This highfrequency filter ensures that the negative extremes produced are the result of poor growth in a particular calendar year relative to the previous one and not due to a poor year among a period of poorer growth years. If one wanted to look at decade-long periods of poorer growth (to consider the lowerfrequency volcanic forcing ideas of Miller et al., [2012]) then an alternate standardization strategy should be implemented. In this study with the TRW series, our aim is to consider the possible effects of major volcanic events regardless of whether they occurred in cooler or warmer periods.

[8] A 10-year spline was similarly fitted to the JuneAugust (JJA) average temperature from the long instrumental record to leave high-pass residuals. This is done to see if the cool summers that have been measured coincide with the tree-ring series and the volcanic events over the period from the early 19 th century.

[9] Before discussing the results of the analyses with TRW, it is worth considering the possible differences or similarities with measurements using the more commonly analyzed (in the volcanic context) MXD data. Analyses of instrumental data [e.g., Jones et al., 2003] and longer MXD data from trees [Briffa et al., 1998] have always emphasized very cold individual summers/values rather than variability on timescales beyond decadal. MXD measurements are generally related to photosynthesis during the year of measurement and over a longer part of the growing season [Körner, 2012] and therefore potentially more related to changes in optical properties resulting from volcanic eruptions. This potentially makes them more suitable than TRW for investigating single events such as volcanic eruptions. However, their length is often markedly shorter than that for TRW. Ideally, it would be very useful to analyze all the subfossil material for MXD along with the TRW that has been measured. Until recently, this has not been possible, but the work of Helama et al. [2012], Gunnarson et al. [2011], Esper et al. [2012], and McCarroll et al. [2013] shows promise in being able to measure MXD from this type of material.

\section{Discussion of Results for TRW}

[10] Figure 1 shows the 10-year smoothed residual series for the JJA summer temperature average for TornedalenHaparanda from 1802. The most anomalous low-index summers were $1821,1856,1902$, and 1923. Of these, the only recognized volcanic year is 1902 (see Table 1). Other volcanic years in this table are not very evident, a clear illustration that it is much harder to see volcanic signals at single sites as opposed to large-area averages. In this record, the summer of 1816 is not a cold extreme, being just marginally below the long-term average. This summer was much colder in more southern and western parts of Europe [see, e.g., Jones et al., 2003] but is clearly not an extreme in northern Fennoscandia.

[11] Figure 2 shows the 10-year high-pass TRW chronologies, plotting the series for the two sets of TRW data. As over 7000 years of data are plotted, we spilt the period into panels of 1000 years and provide correlations between the two series for each panel. For the BC panels, the first value plotted is for $1 \mathrm{BC}$, which was the year that preceded $\mathrm{AD}$ 1. We additionally highlight with an asterisk the 20 most negative extremes (calculated over the whole period of record) in both series. This shows that only 5 years in the two series of the 20 most negative extremes coincide. Interseries correlations are similar for earlier 1000-year segments but reduce markedly for the period before $4000 \mathrm{BC}$, possibly as replication at the sites tends to reduce further back in time. Because of the high correlation (and thus a shared common signal) between the two sites, trees from both sites are equally likely to contain this high-frequency common signal, and the average of all trees (which is the count weighted average of the two chronologies) is likely to have less noise than either individual site. The reduction in agreement could also be interpreted as there being less extreme years in the two regions in earlier periods, but as the reduction is small, it could just be due to chance. We investigate this in the next paragraph.

[12] In Figure 3, we plot the count-weighted average of the two series, with weights determined by the number of TRW values available for each year. As there are generally more samples through time for the Finnish series, this generally gets a slightly higher weight compared to the Swedish series. As with Figure 2, the 20 most extreme negative years are plotted with an asterisk. For both locations, there is a slight tendency for the interannual variability of each panel to reduce for earlier 1000-year segments. We investigated whether this is significant in two ways. First, we looked at the variance of the first 2500 years (5500-3000 BC) compared to the last 2500 years (504 BC to AD 1997). An F-test indicates that for the earlier period, the variance is lower, at 
JONES ET AL.: NORTH EUROPEAN SUMMERS AND VOLCANOES
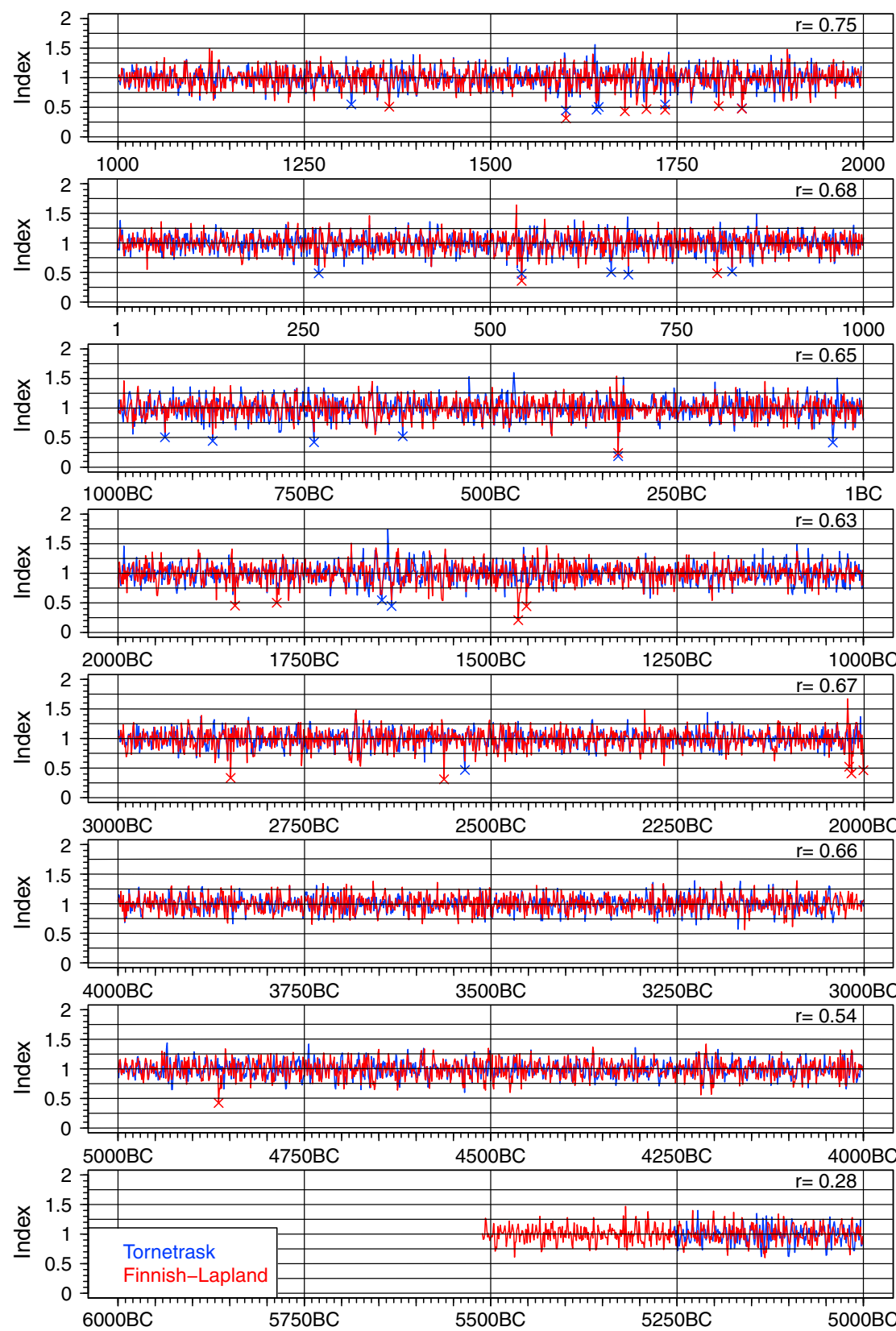

Figure 2. Mean tree indices from the 10-year high-pass signal-free standardization of TRW data for the two northern Fennoscandian sites (Torneträsk in Blue and Finnish-Lapland in Red). The correlations between the series for each 2000-year panel are given. The asterisks mark the lowest 20 values of each series, over its entire length.

the $95 \%$ significance level. Second, we looked at a large number of extremes (the top 100) and additionally looked at the positive as well as negative extremes. Positive extremes will have a variety of causes, but the aim here is to see if they are also low when the count of negative ones is low implying that the standardization might be a factor. The first 2500 years (5500-3000 BC) only have seven negative extremes, whereas the other 93 are in the period since $3000 \mathrm{BC}$ (a period that is twice as long at $\sim 5000$ years). For positive extremes, the same periods have 26 and 74 positive extremes. This test additionally indicates fewer positive extremes but nowhere near as marked as for the negative ones. We conclude, therefore, that the variance of the first
2500 years is lower, possibly due to this mid-Holocene period being warmer resulting in fewer negative extremes but not as a function of the standardization process as a similar reduction in positive extremes doesn't occur.

[13] As stated earlier, most of the data after AD 1000 come from living trees or dead material still lying on the ground while much of the earlier material is subfossil. Also, as the number of samples per year increases, this likely increases the representation of the temperature signal in the chronology. Reduced replication may be a factor in the reduced variability in earlier millennia, but it must be remembered that this is for higherfrequency versions of the two chronologies. Intercorrelation between the two series is reduced in the first 1500 years, likely 
JONES ET AL.: NORTH EUROPEAN SUMMERS AND VOLCANOES
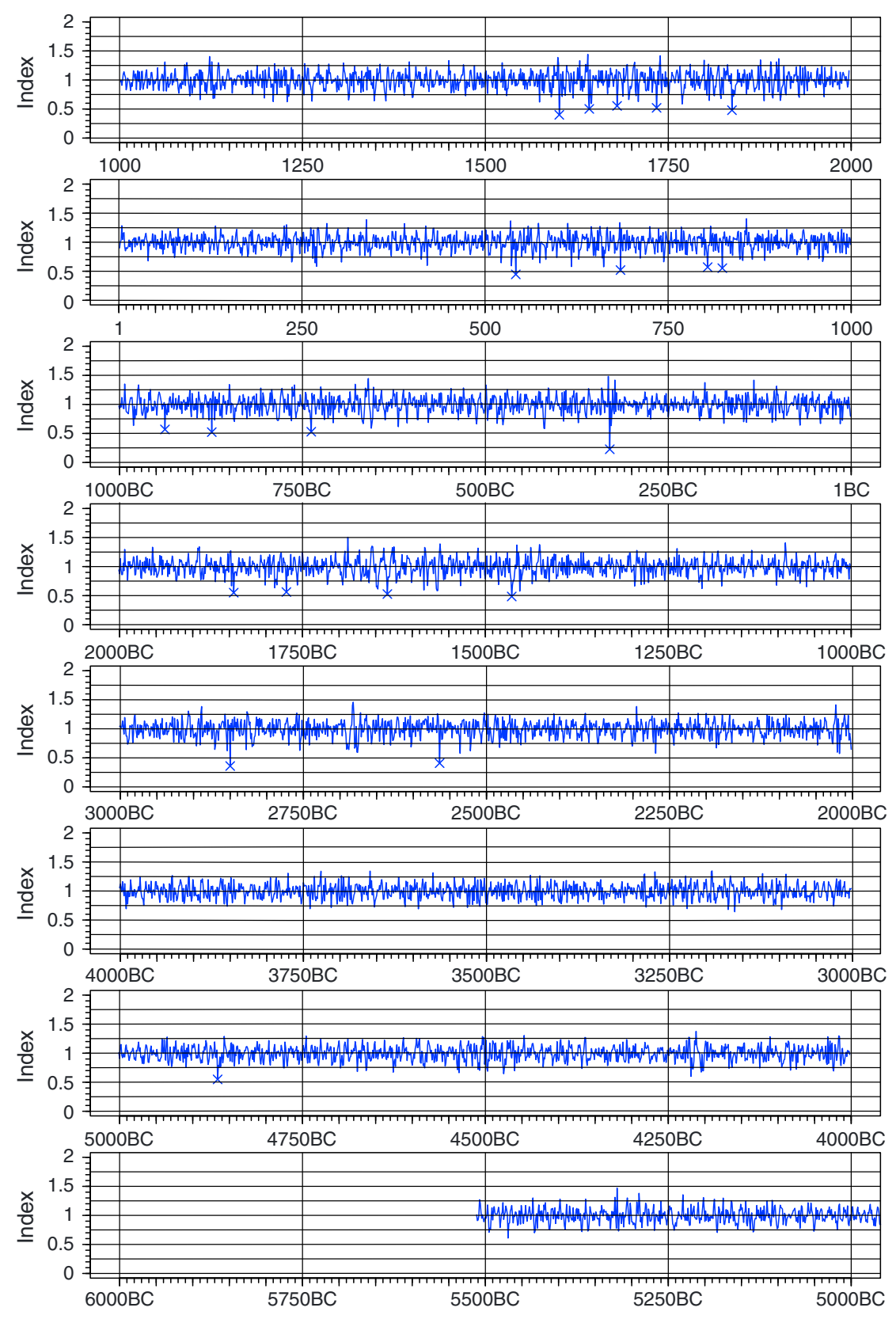

Figure 3. Mean tree indices from the 10-year high-pass signal-free standardization of TRW data for the two northern Fennoscandian sites. Weights were determined from the number of samples from the two locations for each year. The asterisks mark the lowest 20 values of the series, over its entire length.

due to smaller sample counts and increased noise-producing reduced clarity of the expression of the chronology signal.

[14] Finally, the starred extreme years in all these plots have a tendency to cluster with some periods recording several negative extremes while other extended periods are devoid of such extremes. In Figure 4, we plot the last 2000 years in panels of 500 years. Clustering is evident in the weighted average series with three of the nine extremes from Table 2 occurring in the 17th century. This century has the most extremes of the last 7000 years.

[15] The ranking of the most extremely negative years differs between the two locations. Table 2 lists the top twenty extremes across the whole period of record. Nine of the 20 years are in the last 2000 years, with the other 11 being in the more than 5000 years before. The two most extremely negative years of the AD part of the series are 1601 and 542: 1601 was the sixth most extreme for Sweden and fourth for Finland, and 542 was tenth for Sweden and sixth for Finland. The only other AD year in the top 20 years when determined separately for each site is 1837 (twelfth for Sweden and fifteenth for Finland). This year occurs two years after the Cosiguina eruption in 1835 (see Table 1) but is not extreme in the Tornedalen instrumental record (see Figure 1). The year 1601 has been similarly determined in a study by Helama et al. [2013], who also note the extreme year of 542 , but they found that 536 was more severe (also noted by Baillie, [2008] and Larsen et al., [2008]). Here 536 is the 36 th most extreme year in the weighted series. The 

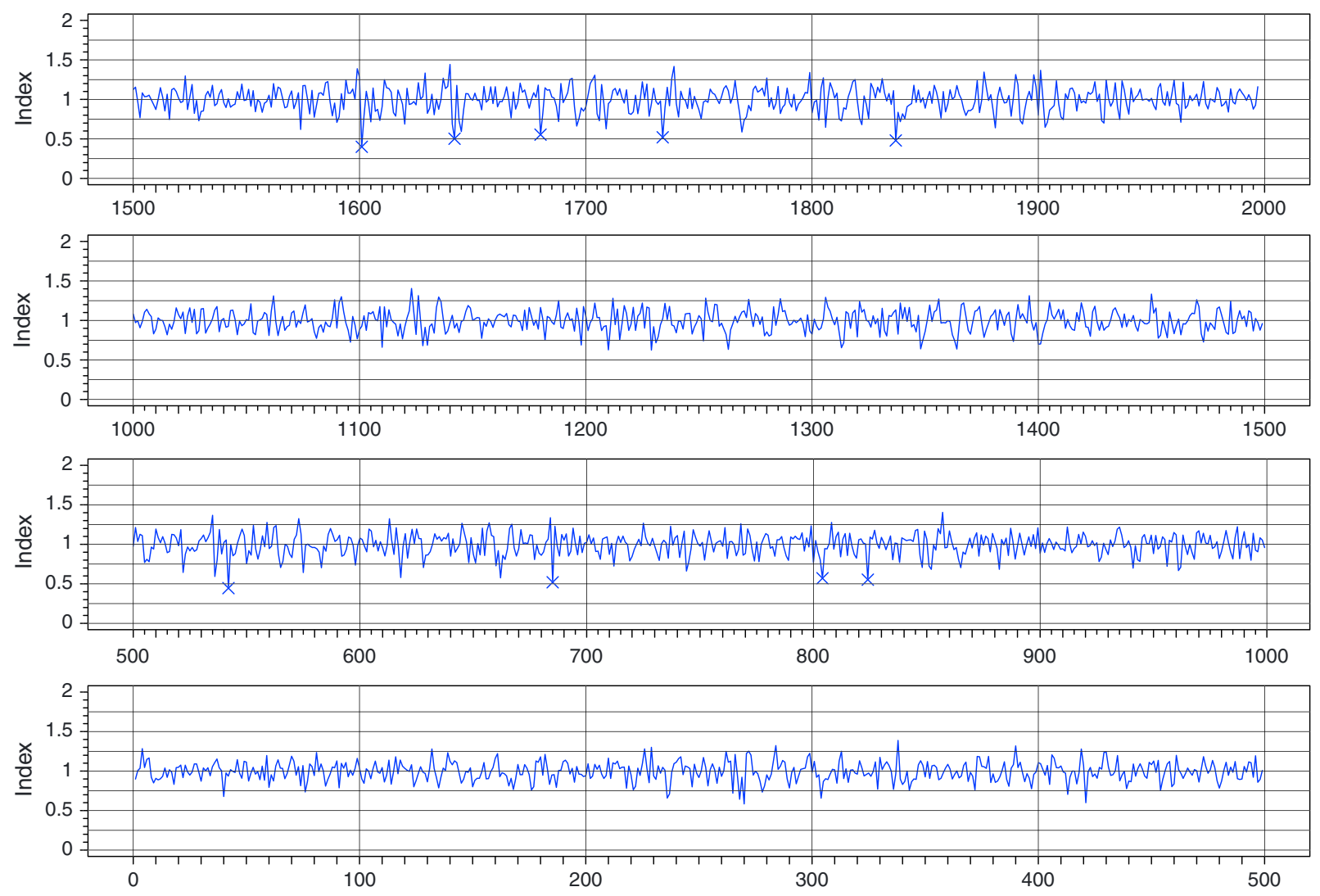

Figure 4. The last 2000 years for the mean tree indices from the 10-year high-pass signal-free standardization of the two Fennoscandian sites. The asterisks mark the lowest 20 values of the series, over its entire length (i.e., just those years in the AD period are shown).

Briffa et al. [1998] study using MXD found 1601 as the most extreme year between 1400 and 1990. This year occurs the year after the eruption of Hyuanaputina in Peru in 1600 [see Simkin and Siebert, 1994]. The other AD years in the top 20 most negative years for the weighted average are $1642,685,1734,824,1680$, and 804 in rank order. As implied from the above, these years only appear in the top 20 in one of the two TRW series. Of these years, only 1642 can be associated with a volcano (Mt. Parker in the Philippines, [Siebert et al., 2011]) in the year before. Of the four most negative years in the Tornedalen instrumental record, only 1902 is in the list of volcanic years in Table 1.

[16] In the BC years, only one year is ranked in both top 20 TRW series, $330 \mathrm{BC}$. This year was the most negative overall year in Sweden and the second most negative for Finland. The fact that this year is so extreme in both series attests to the cross-dating agreement in both series. Other BC years in the combined top 20 listing are $2850,2564,1464,874$, $1634,738,4866,1844,1772$, and 983 in rank order. Only one of these years $(1772 \mathrm{BC})$ coincides with the long bristlecone pine series developed by Salzer and Hughes [2007]. Another long series from the Austrian Alps [Nicolussi et al., 2009] would also be useful to compare with, but this paper does not emphasize the year-to year extremes. It is important to undertake comparisons of the extremes in these and other long TRW series, but for comparisons to be meaningful, the standardization will need be performed in a similar way. Assessing whether any of these dates coincides with volcanoes is not possible as all ice core dates have layer counting problems of at least 2-3 years before the earliest known eruption date (which was Vesuvius in AD 79, [Vinther et al., 2006]). Based on the $\mathrm{AD}$ period when major volcanic dates are more precise, some, but not all, could be volcanic years.

Table 2. The Top 20 Most Negative Years in the Weighted Average ${ }^{\mathrm{a}}$

\begin{tabular}{lccccc}
\hline Rank & Year & Value & $\begin{array}{c}\text { Torn Core } \\
\text { Count }\end{array}$ & $\begin{array}{c}\text { Fin Core } \\
\text { Count }\end{array}$ & $\begin{array}{c}\text { Total Core } \\
\text { Count }\end{array}$ \\
\hline 1 & -330 & 0.228 & 3 & 9 & 12 \\
2 & -2850 & 0.359 & 5 & 40 & 45 \\
3 & 1601 & 0.400 & 88 & 49 & 137 \\
4 & -2564 & 0.408 & 18 & 37 & 55 \\
5 & 542 & 0.446 & 45 & 18 & 63 \\
6 & 1837 & 0.480 & 111 & 53 & 164 \\
7 & -1464 & 0.485 & 10 & 14 & 24 \\
8 & 1642 & 0.502 & 71 & 44 & 115 \\
9 & 685 & 0.520 & 62 & 41 & 103 \\
10 & 1734 & 0.520 & 64 & 32 & 96 \\
11 & -874 & 0.522 & 11 & 24 & 35 \\
12 & -1634 & 0.527 & 3 & 10 & 13 \\
13 & -738 & 0.529 & 15 & 23 & 38 \\
14 & -4866 & 0.549 & 6 & 14 & 20 \\
15 & -1844 & 0.551 & 17 & 15 & 32 \\
16 & 824 & 0.553 & 57 & 50 & 107 \\
17 & 1680 & 0.554 & 70 & 43 & 113 \\
18 & -1772 & 0.562 & 18 & 15 & 33 \\
19 & -938 & 0.569 & 13 & 36 & 49 \\
20 & 804 & 0.570 & 59 & 51 & 110 \\
\hline
\end{tabular}

${ }^{\mathrm{a}}$ Negative years are BC. 


\section{Conclusions}

[17] In terms of the agreement between known volcanic dates and the cold summers recorded by the trees in northern Fennoscandia, the results are nowhere near as conclusive as those from some of the earlier studies that used MXD. There are a number of reasons for this. First, analyses of the instrumental record using SEA were much more significant when they considered the whole land area of the $\mathrm{NH}$, as opposed to looking at Europe alone. Second, studies like that by Briffa et al. [1998] used many more series extending across all the high-latitude and high elevation areas of the $\mathrm{NH}$ north of $20^{\circ} \mathrm{N}$. Finally, it has been shown in many studies [e.g., Jones et al., 1995] that MXD variability is much more spatially coherent than TRW, and also, MXD generally correlates higher with summer temperatures than TRW.

[18] This study and Helama et al. [2013] have shown potential for the use of the extended TRW series, but these need to be spatially expanded to bring in many more chronologies from other higher latitude and higher elevation areas of the $\mathrm{NH}$. It is unlikely that there are many TRW chronologies this long, but there are a number that extend back at least 2000 years. It is likely to be very important to use TRW series that clearly respond to summer temperature and to bring in material from as many locations as possible. Quicker progress is likely to be achieved by developing long MXD series in Northern Fennoscandia as this tree-ring measure more clearly responds to negative temperature extremes than TRW.

[19] Acknowledgments. This work has been supported by the USDoE (Grant DE-SC0005689) and the Academy of Finland (Grant 251441). HG acknowledges the Royal Swedish Academy of Sciences (FOA09V-063) and TMM support from NERC (NE/G018863/1). We thank Danny McCarroll in particular and two anonymous reviewers for their reviews and suggestions on the paper.

\section{References}

Baillie, M. G. L. (2008), Proposed re-dating of the European ice core chronology by seven years prior to the 7 th century AD, Geophys. Res. Lett., 35, L15813, doi:10.1029/2008GL034755.

Böhm, R., P. D. Jones, J. Hiebl, D. Frank, M. Brunetti, and M. Maugeri (2010), The early instrumental warm-bias: a solution for long Central European temperature series, 1760-2007, Clim. Change, 101, 41-67.

Briffa, K. R., P. D. Jones, F.H. Schweingruber, and T.J. Osborn (1998), Influence of volcanic eruptions on Northern Hemisphere summer temperature over the last 600 years, Nature, 393, 450-455.

Eronen, M., P. Zetterberg, K.R. Briffa, M. Lindholm, J. Meriläinen, and M. Timonen (2002), The supralong Scots pine treering record for Finnish Lapland: part 1, chronology construction and initial references, Holocene, 12, 673-680.

Esper, J., et al. (2012), Orbital forcing of tree-ring data, Nat. Clim. Change, 2, 862-866, doi:10.1038/CLIMATE1589.

Grudd, H., K. R. Briffa, W. Karlén, T. S. Bartholin, P. D. Jones, and B. Kromer (2002), A 7400-year tree-ring chronology in northern Swedish Lapland: natural climatic variability expressed on annual to millennial timescales, Holocene, 12, 657-665.

Gunnarson, B. E., H. W. Linderholm, and A. Moberg (2011), Improving a tree-ring reconstruction from west-central Scandinavia: 900 years of warm-season temperatures, Clim. Change, 36, 97-108, doi:10.1007/ s00382-010-0783-5.
Helama, S., K. Mielikäinen M. Timonen, and M. Eronen (2008), Finnish supra-long tree-ring chronology extended to 5634 BC, Nor. Geogr. Tidsskr., 62, 271-277.

Helama, S., Y. Bégin, M. Vartiainen, H. Peltola, T. Kolström, and J. Meriläinen (2012), Quantifications of dendrochronological information from contrasting microdensitometric measuring circumstances of experimental wood samples, Appl. Radiat. Isot., 70, 1014-1023.

Helama, S., J. Holopainen, M. Macias-Fauria, M. Timonen, and K. Mielikänen (2013), A chronology of climatic downturns through the mid and late Holocene - Tracing the distant effects of explosive eruptions from palaeoclimatic and historical evidence in Northern Europe, Polar Rec., 32, doi:10.3402/polar.v32i0.15866.

Jones, P. D., K. R. Briffa, and F. H. Schweingruber (1995), Tree-ring evidence of the widespread effects of explosive volcanic eruptions, Geophys. Res. Lett., 22, 1333-1336.

Jones, P. D., A. Moberg, T. J. Osborn, and K. R. Briffa (2003), Surface climate responses to explosive volcanic eruptions seen in long European temperature records and mid-to-high latitude tree-ring density around the Northern Hemisphere, in Volcanism and the Earth's Atmosphere Geophys. Monogr. Ser., vol. 139, edited by A. Robock and C. Oppenheimer, pp. 239-254, AGU, Washington, D. C.

Klingbjer, P., and A. Moberg (2003), A composite monthly temperature record from Tornedalen in northern Sweden, 1802-2002, Int. J. Climatol., 23, 1465-1494.

Körner, C. (2012), Alpine Treelines: Functional Ecology of the Global High Elevation Tree Limits, 220 pp., Springer, Basel, Switzerland, doi:10.1007/ 978-3-0348-0396-0.

Larsen, L. B., et al. (2008), New ice core evidence for a volcanic cause of the A.D. 536 dust veil, Geophys. Res. Lett., 35, L04708, doi:10.1029/ 2007GL032450.

McCarroll, D., et al. (2013), A 1200- year multi-proxy record of tree growth and summer temperature at the northern pine forest limit of Europe, Holocene, 23, 471-484, doi:10.1177/0959683612467483.

Melvin, T. M. and K. R. Briffa (2008), A 'signal-free' approach to dendroclimatic standardisation, Dendrochronologia, 26, 71-86.

Melvin, T. M., H. Grudd, and K. R. Briffa (2013), Potential bias in 'updating' tree-ring chronologies using regional curve standardisation: Re-processing 1500 years of Torneträsk density and ring-width data, Holocene, 23, 364-373, doi:10.1177/0959683612460791.

Miller, G. H., et al. (2012), Abrupt onset of the Little Ice Age triggered by volcanism and sustained by sea-ice/ocean feedbacks, Geophys. Res. Lett., 39, L02708, doi:10.1029/2011GL050168.

Newhall, C. G., and S. Self(1982), The volcanic explosivity index (VEI): An estimate of explosive magnitude for historical volcanism, J. Geophys. Res., 87, 1231-1238, doi:10.1029/JC087iC02p01231.

Nicolussi, K., M. Kaufmann, T. M. Melvin, J. van der Plicht, P. SchießLing, and A. Thurner, (2009), A 9111-year long conifer tree-ring chronology for the European Alps: A base for environmental and climatic investigations, Holocene, 19, 909-920.

Osborn, T. J., K. R. Briffa, and P. D. Jones, (1997), Adjusting variance for sample-size in tree-ring chronologies and other regional-mean timeseries, Dendrochronologia, 15, 89-99.

Robock, A. (2000), Volcanic eruptions and climate, Rev. Geophys., 38, 191-219.

Robock, A., and J. Mao (1992), Winter warming from large volcanic eruptions, Geophys. Res. Lett., 19, 2405-2408.

Salzer, M. W., and M. K. Hughes, (2007), Bristlecone pine tree rings and volcanic eruptions over the last 5000 years, Quat. Res., 67, 57-68.

Sear, C. B., P. M. Kelly, P. D. Jones, and C. M. Goodess (1987), Global surfacetemperature responses to major volcanic eruptions, Nature, 330, 365-367.

Siebert, L., T. Simkin, and P. Kimberly (2011), Volcanoes of the World, 3rd ed., 568 pp., Univ. of Calif. Press and Smithsonian Institution, Berkeley, Calif.

Simkin, T., and L. Siebert (1994), Volcanoes of the World, 2nd ed., 349 pp., Geoscience, Tucson, Ariz.

Simkin, T., L. Siebert, L. McClelland, D. Bridge, C. G. Newhall, and J. H. Latter (1981), Volcanoes of the World, vol. 2, 32 pp., Van Nostrand Reinhold, New York.

Vinther, B. M., et al. (2006), A synchronized dating of three Greenland ice cores throughout the Holocene, J. Geophys. Res., 111, D13102, doi:10.1029/2005JD00692. 